\title{
Traumatic anterior dislocation of the hip
}

\author{
Aoife Granahan, ${ }^{1}$ Nuala McAuley, ${ }^{2}$ Prasad Ellanti, ${ }^{3}$ Niall Hogan ${ }^{1}$
}

'Saint James's Hospital, Dublin, Ireland

${ }^{2}$ Department of Orthopaedics, St James's Hospital, Dublin, Ireland

${ }^{3}$ Department of Trauma and Orthopaedics, St James's Hospital, Dublin, Ireland

\section{Correspondence to}

Dr Aoife Granahan, aoifegranahan89@gmail.com

Accepted 18 August 2016
CrossMark

To cite: Granahan $\mathrm{A}$, McAuley N, Ellanti $\mathrm{P}$, et al. BMJ Case Rep Published online: [please include Day Month Year] doi:10.1136/ bcr-2016-216629

\section{DESCRIPTION}

A 31-year-old male motorcyclist presented to the emergency department(ED) following a road traffic accident with significant right hip pain and inability to weight bear. On examination the patient had a shortened and externally rotated leg with absent peripheral pulses and cold peripheries concerning for vascular compromise. A plain radiograph demonstrated an anterior hip dislocation (AHD) with a greater trochanter (GT) fracture (figure 1). An urgent CT of the pelvis was performed to exclude the possibility of a femoral neck fracture (figure 2A, B). The hip was reduced under conscious sedation in the ED using the Allis method. The peripheral pulses returned. A further CT angiogram of the pelvis was performed which showed concentric reduction, an undisplaced GT fracture and a short segment dissection of the right external iliac artery which was managed conservatively as directed by the vascular team (figure $3 \mathrm{~A}, \mathrm{~B}$ ). The patient was mobilised full weight bearing as tolerated with physiotherapy. He has a stable and pain-free hip with a healing GT fracture at his 6-week follow-up (figure 4).

Hip dislocations are uncommon accounting for $5 \%$ of all dislocations with AHDs accounting for $15 \%$ of all hip dislocations ${ }^{1}$ AHDs are frequently are associated with fractures of the acetabulum or

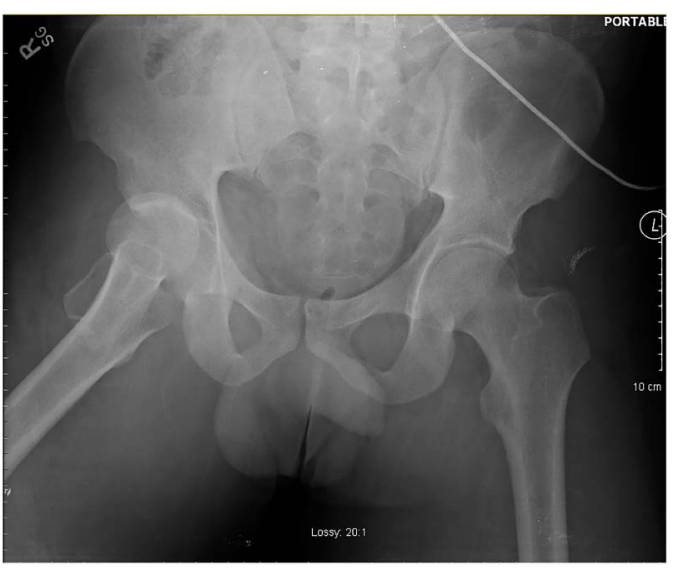

Figure 1 Plain radiograph anteroposterior; left hip. Anterior dislocation of the left hip with fracture of the greater trochanter.

proximal femur. They can be associated with vascular compromise either by injury to the vessels or by compression from the dislocated femoral head. ${ }^{2}$ These need to be reduced as soon as possible ideally under a general anaesthetic in operation theatre but if delays are expected reduction should be attempted in the ED to minimise the risk of avascular necrosis. $^{3}$
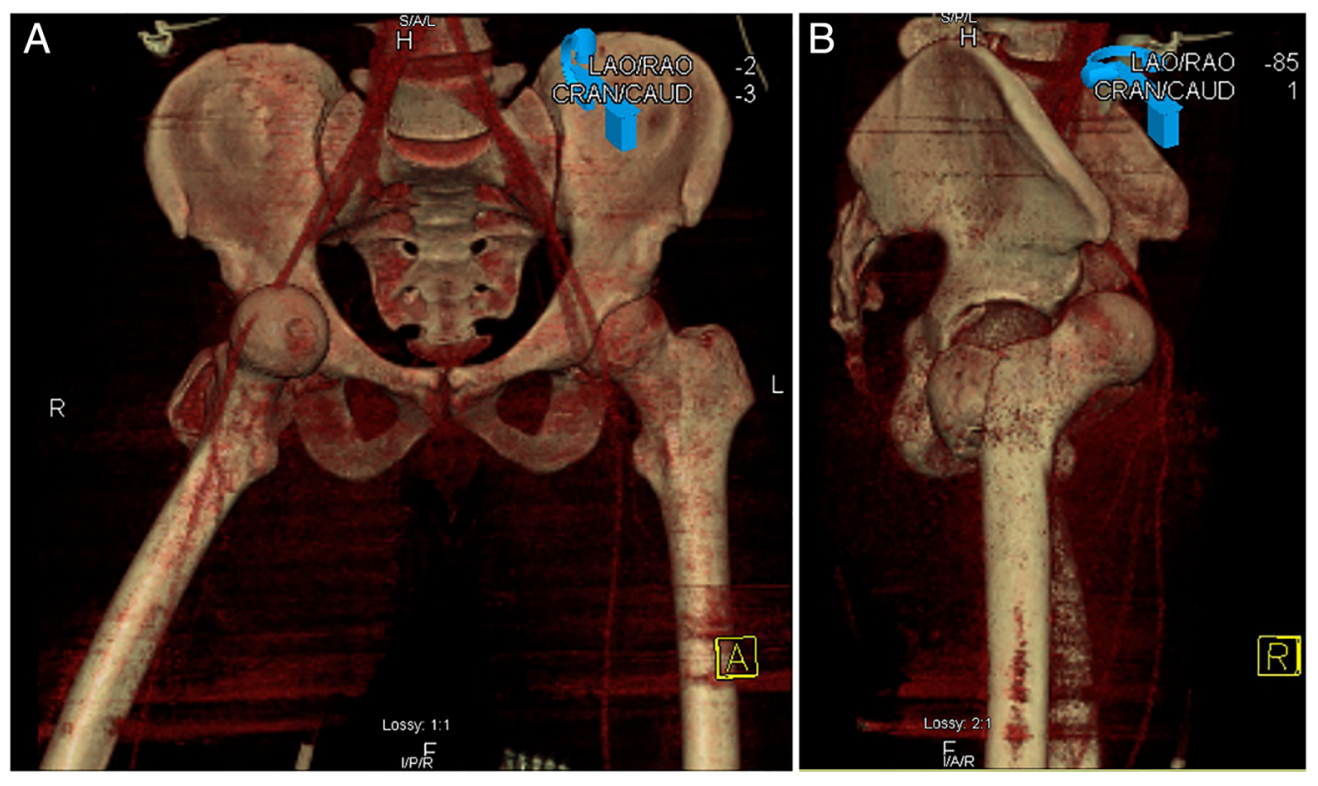

Figure 2 (A) CT coronal image of the pelvis with three-dimensional reconstruction. Anterior dislocation of the left femoral head from the acetabulum. Proximity and compression of the femoral vessels can be appreciated. (B) CT sagittal image of the pelvis with three-dimensional reconstruction. Anterior dislocation of the left femoral head from the acetabulum with compression of the right femoral vessels. 

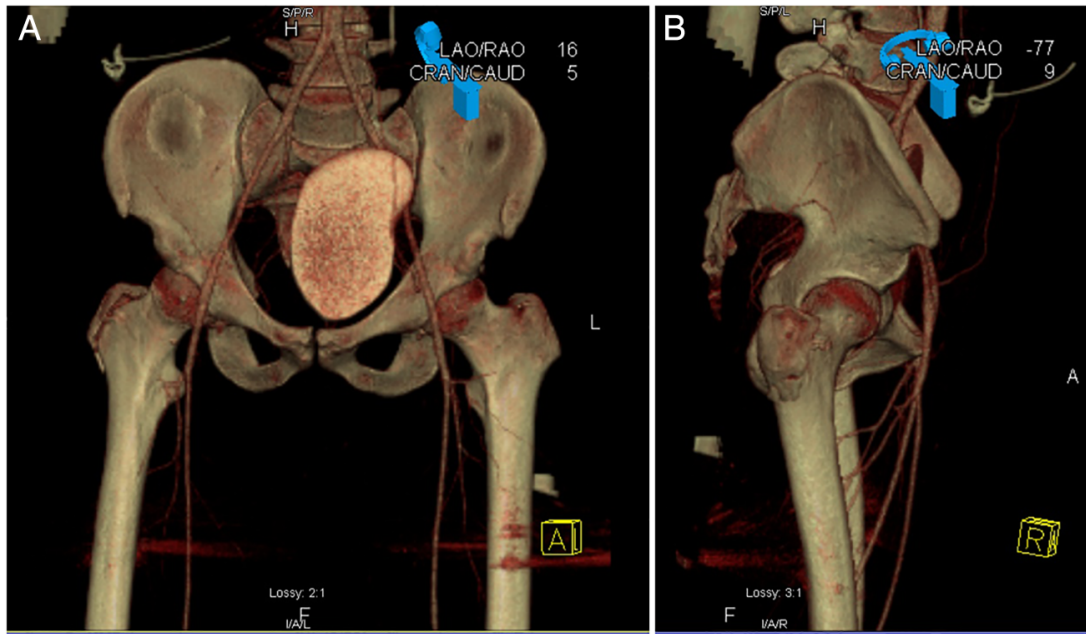

Figure 3 (A) CT coronal image of the pelvis with three-dimensional reconstruction. Anatomical reduction of the left hip using Allis method. There is an undisplaced fracture of the greater trochanter with short segment dissection of the right external iliac artery. (B) CT sagittal image of the pelvis with three-dimensional reconstruction. Postanatomical reduction with dissection of the right external iliac artery.

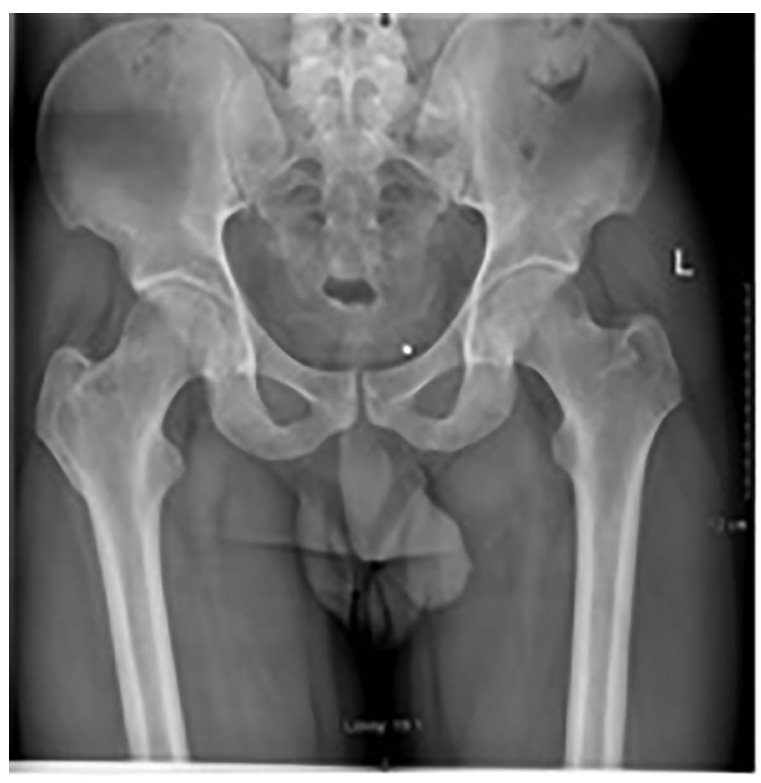

Figure 4 Pelvic radiograph anteroposterior. Follow-up imaging at 6 weeks. Stable reduction of the left hip with undisplaced fracture of the greater trochanter.

Contributors $A G$ and PE performed the literature review. AG and NMCA obtained and formatted the images. NH supervised the writing of the manuscript and treated the patient.

\section{Learning points}

- Hip dislocations are uncommon accounting for $5 \%$ of all dislocations with anterior hip dislocations accounting for $15 \%$ of all hip dislocations.

- They are frequently associated with fractures of the acetabulum or proximal femur and with vascular injury.

- They should be reduced as soon as possible under a general anaesthetic but if delays are expected reduction should be attempted in the emergency department to minimise the risk of avascular necrosis.

Competing interests None declared.

Patient consent Obtained.

Provenance and peer review Not commissioned; externally peer reviewed.

\section{REFERENCES}

1 Sahin V, Karakaş ES, Aksu S, et al. Traumatic dislocation and fracture-dislocation of the hip: a long term follow-up study. J Trauma 2003;54:520-9.

2 Bastian JD, Turina M, Siebenrock KA, et al. Long-term outcome after traumatic anterior dislocation of the hip. Arch Orthop Trauma Surg 2011;131:1273-8. doi: 10.1007/s00402-011-1299-0. Epub 2011 Mar 20.

3 Epstein HC, Wiss DA, Cozen L, et al. Traumatic anterior dislocations of the hip: management and results, an analysis of fifty five cases. J Bone Joint Surg Am 1972; 54(7):1561-2.

Copyright 2016 BMJ Publishing Group. All rights reserved. For permission to reuse any of this content visit http://group.bmj.com/group/rights-licensing/permissions.

BMJ Case Report Fellows may re-use this article for personal use and teaching without any further permission.

Become a Fellow of BMJ Case Reports today and you can:

- Submit as many cases as you like

- Enjoy fast sympathetic peer review and rapid publication of accepted articles

- Access all the published articles

- Re-use any of the published material for personal use and teaching without further permission

For information on Institutional Fellowships contact consortiasales@bmjgroup.com

Visit casereports.bmj.com for more articles like this and to become a Fellow 